ORIENTAL JOURNAL OF CHEMISTRY

An International Open Free Access, Peer Reviewed Research Journal

www.orientjchem.org
ISSN: 0970-020 X

CODEN: OJCHEG

2017, Vol. 33, No.(5):

Pg. 2625-2631

\title{
Extraction of Methylcellulose from Wheat Straw of Himachal Pradesh, India
}

\author{
SWADESH KUMAR ${ }^{\star 1}$ and YOGESH KUMAR WALIA**2 \\ ${ }^{1}$ Research Scholar, Department of Chemistry, Career Point University, Kota (Rajasthan), India. \\ 2Department of Chemistry, School of Basic \& Applied Sciences, Career Point University, Hamirpur \\ (Himachal Pradesh), India. \\ ${ }^{\star}$ Corresponding author E-mail : swadeshkumar19@gmail.com
}

http://dx.doi.org/10.13005/ojc/330560

(Received: June 07, 2017; Accepted: July 01, 2017)

\begin{abstract}
Non-wood fibers are one of the chief sources for the spongy soaked group of fibers and paper production in developing countries caused by their profusion and cost value. Wheat Straw is the agricultural by-product obtained from different parts of Wheat plant like stem, leaves etc. Wheat Straw is rich in cellulosic fibers, Holocellulose and Ash Content. All these elements together make Wheat Straw as most significant and balanced source for Cellulose and cellulosic derivatives, microbial cultures for its varied applications in fermentation, food, feed, medicine industries, in fields to raise soil fertility etc. It is the low cost source of natural substance. Wheat Straw used in this study for the synthesis of Cellulose and Methylcellulose. This study was carried out according to TAAPI standard and other procedures and the results shows that Ash Content has been found higher in Wheat Straw. Holocellulose and Alpha-cellulose in Wheat Straw has been found little lesser than wood. Wheat Straw is highly dissolved in alkali than wood caused by it uses less cooking chemicals.
\end{abstract}

Keywords: Wheat Straw, Lignin, Alpha-cellulose and Holocellulose

\section{INTRODUCTION}

Generally wood is more costly than non-wood. Wood is the vital wellspring of Cellulose for manufacturing paper. Like wise with the enlargement of paper ventures in the nation, mash containing plants are being utilized to a calculable level ${ }^{26}$. Wood is difficult to transport yet issues with non wood plants are gathering, stockpiling and high fiery debris content ${ }^{27}$. Now wood is not accessible in sufficient quantities as of the rising consumption in furniture, construction, paper, paperboard and cellulose derivatives etc ${ }^{2,9,11}$. Because of overproduction of agriculture crops, abundance and cost-effectiveness the probable main source for the pulp and paper industries at this time is non-wood in rising countries because of greater yield of Cellulose, lignin materials less in sums in non-wood and usage of littler sum chemicals and energy ${ }^{2,5,6,7,12,13}$. Non-wood has practically indistinguishable substance constituents like have wood plants, for example, Cellulose, Hemicellulose, Lignin and Extractives. The nearby chemical analysis of a variety of uncooked materials 
exhibit that nearly all wood enclose approximately $30-40 \%$ non-cellulose component which consist of ash content, Lignin and Extractives etc $^{25}$. Wheat Straw is primarily composed of Cellulose, hemicellulose and lignin ${ }^{10}$. More than 600 million tons Wheat Straw is yielded yearly entire of the world, most of Wheat Straw are singed in the ground deliver major environmental and wellbeing dangers. Wheat Straw is non-wood agricultural waste which is serving as an excellent fibrous material to recycle into quality paper in many parts of the globe. Attractive thoughtful of the physical and concoction properties of Wheat Straw is required for the usage of matter for different applications. The analyses were carried out according to TAAPI standard procedures and the results of Physico-Chemical analysis of Wheat Straw revealed that the different conditions such as climatic conditions, soil fertility, fertilizer used etc. have little effects on the analysis at different Sampling Sites.

\section{MATERIALS AND METHODS}

\section{Sampling Sites}

In order to assess the Physical and Chemical analysis of Wheat Straw from Himachal Pradesh, India according to different climatic conditions, different soil fertility, use of fertilizer etc. four sampling site have been selected i.e. First Sampling site (S1) - Distt. Hamirpur, Himachal Pradesh; Second Sampling site (S2) - Distt. Bilaspur, Himachal Pradesh; Third Sampling Site (S3) - Distt. Kangra, Himachal Pradesh and Fourth Sampling Site (S4) - Distt. Mandi, Himachal Pradesh. Samples are collected from May, 2015 for this analysis.

\section{Experimental}

Extraction of Methylcellulose and chemical examination of wheat straw is all in all yielded by TAPPI ordinary techniques (T 211om 02, T $207 \mathrm{~cm}$ 97, T 212 om 02, T $204 \mathrm{~cm} \mathrm{97,} \mathrm{T} 223$ cm 84, T 222 om $02, \mathrm{~T} 203 \mathrm{~cm} \mathrm{99).} \mathrm{It} \mathrm{is} \mathrm{tried} \mathrm{for} \mathrm{the} \mathrm{accompanying}$ as Ash content, Cold and Hot water solubility, Alcohol -benzene solubility, 1\% sodium hydroxide $(\mathrm{NaOH})$ solubility, Lignin content, Pentosan content, Holocellulose and Alpha cellulose for four different district of Himachal Pradesh such as Hamirpur, Bilaspur, Kangra and Mandi.

\section{Ash content (T 211 om 02) ${ }^{20}$}

Take crucible and clean with distilled water. Cauldrons dry in oven and after that cool at normal temperature. Measure the Weight of Cauldrons on the electronic balance. Add $10 \mathrm{~g}$ sample in crucible and cover a jar. Put the Cauldrons in furnace. Increase the temperature up to $525 \pm 3^{\circ} \mathrm{C}$ step by step so test progresses toward becoming carbonized with warming. Sample cannot be destroying by heating; it can be changed only char. Charred materials Cauldrons taken out from the furnace and allow cooling at room temperature. Weigh the Cauldrons with ash and calculate Ash content.

\section{Cold water solubility (T $207 \mathrm{~cm} \mathrm{97)22}$}

Add $10 \mathrm{~g}$ sample in a beaker and add distilled water in a beaker slowly. Bring out extraction $23^{\circ} \mathrm{C}$ with constant stirring for 48 hours. Transfer the material to tarred filtering Cauldrons which have been dried on $105 \pm 3^{\circ} \mathrm{C}$. After that washed with icy refined water and got dried out to a perpetual weight at $105^{\circ} \mathrm{C}$. Place the heated Cauldrons in a tarred, loosely stopper weighing bottle and cool in desiccators before weighing.

\section{Hot water solubility (T $207 \mathrm{~cm} \mathrm{97)22}$}

A $10 \mathrm{~g}$ of sample was taken which are oven dried and put into a $250 \mathrm{ml}$ level base flask with $100 \mathrm{ml}$ of hot refined water. Put the flask in a bubbling water shower, join the reflux condenser and process for three hours. Extraordinary consideration was given to guarantee that the level of the arrangement in the flask stayed beneath that of the bubbling water. Tests were then expelled from the water shower and sifted by vacuum suction into a fritted glass pot of recognized mass. The deposit was washed with $200 \mathrm{ml}$ of hot faucet water before the cauldrons were stove dried at $105^{\circ} \mathrm{C}$. Cauldrons were then cooled in desiccators and measure the weight.

\section{1\% Sodium Hydroxide solubility (T 212 om 02 )}

Take $10 \mathrm{~g}$ of sample, include $100 \mathrm{ml}$ of $10 \%$ sodium hydroxide $(\mathrm{NaOH})$ in a measuring glass and blend with a glass bar. Cover the measuring glass with a watch glass for the period of $1 \mathrm{hrs}$ in water bath at $97^{\circ} \mathrm{C}$ to $100^{\circ} \mathrm{C}$ and the level above that of the alkali solution in the beaker. Toward the finish of $1 \mathrm{hrs}$, exchange the materials to a tarred separating 
Cauldron and washed with $100 \mathrm{ml}$ of boiling water. At that point include $10 \%$ of acidic corrosive and permit splashing for $1 \mathrm{~min}$. before expulsion. Rehash this progression with a moment wash the material at long last with high temp water until corrosive free.

\section{Alcohol - benzene dissolvability (T $204 \mathrm{~cm} \mathrm{97)}{ }^{16}$}

A $2 \mathrm{~g}$ broiler dried sample was put into an extraction thimble. The thimble was stopped with a little measure of cotton and put in a soxhlet extraction tube. The bubbling jars enclosed a 2:1 arrangement of ethanol and refined toluene individually and were set on a warming mantle. The extraction was led for 8 hours. At the point when the extraction was finished, the greater part of the remaining arrangement was exchanged to the bubbling jar which was warmed on a warming mantle until the arrangement was dissipated. The flask was broiler dried at $103 \pm 2^{\circ} \mathrm{C}$, cooled in desiccators, and measure the weight until a steady weight was gotten.

\section{Pentosan content (T $223 \mathrm{~cm} \mathrm{01)}{ }^{18}$}

3 gram oven dried samples of Wheat Straw were put into $500 \mathrm{ml}$ flat bottom flasks and $300 \mathrm{ml}$ of $13.5 \%$ hydrochloric acid $(\mathrm{HCl})$. Flasks were fixed to pentosan apparatus and boiled the solution. Maintained the acid level in the round bottom flasks by adding $13.5 \%$ hydrochloric acid drop by drop constantly from side to side of separating funnels. Distillate of all samples collected in a volume $220 \mathrm{ml}$ and finished it to $500 \mathrm{ml}$ with distilled water in volumetric flasks. Collected $1 \mathrm{ml}$ from each one mixture was diluted with $100 \mathrm{ml}$ distilled water. The absorbance of distillates was recorded at 280nm using spectrophotometer.

\section{Lignin content (T 222 om 02) ${ }^{17}$}

A $5 \mathrm{~g}$, broiler dried sample of sans extractive Wheat Straw was set in a $150 \mathrm{ml}$ container. $15 \mathrm{ml}$ of icy sulphuric acid $\left(\mathrm{H}_{2} \mathrm{SO}_{4}\right)(72 \%)$ was included slowly while blending and blended well. The response continued for two $h$ with successive mixing in a water shower kept up at $20^{\circ} \mathrm{C}$. At the point when the $2 \mathrm{~h}$ had lapsed, the sample was exchanged by washing it with $560 \mathrm{ml}$ of refined water into a $1,000 \mathrm{ml}$ flask, weakening the convergence of the sulphuric acid to $3 \%$. A condenser was connected to the flask and the contraption was set in a bubbling water shower for 4 hours. At that point, flask was expelled from the water shower and the insoluble matter was permitted to settle. The substance of the flask was separated by vacuum suction into a fritted-glass cauldron of acknowledged mass. The remaining material was washed free of corrosive with $500 \mathrm{ml}$ of hot faucet water and after that broiler dried at $103 \pm 2{ }^{\circ} \mathrm{C}$. Cauldrons were then cooled in desiccators and measure the weight until a steady weight was gotten.

\section{Holocellulose ${ }^{3}$}

A $2 \mathrm{~g}$ sample of broiler dried sans extractive Wheat Straw was measure the weight and set into a $250 \mathrm{ml}$ flask with a little watch glass cover. The sample was then treated with $150 \mathrm{ml}$ of refined water, $0.2 \mathrm{ml}$ of frosty icy glacial acetic acid, and $1 \mathrm{~g}$ of $\mathrm{NaClO}_{2}$ and set into a water shower kept up between 70 to $80^{\circ} \mathrm{C}$. Consistently for five hours $0.22 \mathrm{ml}$ of frosty icy glacial acetic acid and $1 \mathrm{~g}$ of $\mathrm{NaClO}_{2}$ were included and the substances of the flask were mixed continually. Toward the finish of five hours, the flask was set in an ice water shower until the temperature of the flask was decreased to $10^{\circ} \mathrm{C}$. The substances of the flask were shifted into a coarse porosity fritted-glass cauldron of known mass. The cauldrons were then broiler dried at $103 \pm 2^{\circ} \mathrm{C}$, at that point cooled in desiccators, and measure the weight until a consistent weight was come to.

\section{Alpha-cellulose (T $203 \mathrm{~cm} \mathrm{99){ } ^ { 1 9 }}$}

A $3 \mathrm{~g}$ broiler dried specimen of Holocellulose was put in a $250 \mathrm{ml}$ level base flask with a little watch glass cover. The flasks were set into water shower that was kept up at $20^{\circ} \mathrm{C}$. The specimen was processed with $50 \mathrm{ml}$ of $\mathrm{NaOH}$ which is $17.5 \%$ by weight and totally mixed for $1 \mathrm{~min}$. After the sample was permitted to respond with the answer for $29 \mathrm{~min}, 50 \mathrm{ml}$ of refined water was included and blended well for one more moment. The response proceeded for five more minutes. The substance of the flask was sifted by support of vacuum suction into a fritted-glass pot of known mass. The deposit was washed first with $50 \mathrm{ml}$ of $8.3 \% \mathrm{NaOH}$, at that point with $40 \mathrm{ml}$ of $10 \%$ acetic acid. The deposit was washed free of corrosive with $1,000 \mathrm{ml}$ of hot faucet water. The cauldron was broiler dried at $103 \pm 2^{\circ} \mathrm{C}$, at that point cooled in desiccators, and measure the weight until a consistent weight was accomplished. 


\section{RESULTS AND DISCUSSION}

The results of various chemical parameters recorded during present study at all the four sampling sites are presented in Table1 and the examination of different substance parameters at all the four inspecting stations are displayed in Figure.1.

\section{DISCUSSION}

Ash content represents the non-volatile, non-combustible and inorganic part of raw material. In Table.1, the ash content value of sample S1 has found higher $10.01 \%$ and in sample S4 found least $8.9 \%$. It gives the qualitative idea about the minerals and salt present in agriculture residue. In Fig. 1, the value of ash content was seeing approximately equal in all samples. In this study the value of ash content has been found higher than other woods due to the presence of silica ${ }^{4,14}$.

\section{Cold and Hot water solubility}

In Table1, sample S1 value of cold water dissolvability has been higher $6.85 \%$ and S3 has lowest cold water dissolvability $6.52 \%$. cold water dissolvability gives an idea about the low molecular weight compounds. Hot water Solubility of S1 was maximum (13.05\%) and minimum at S3 (12.05\%). Hot water Solubility gives an idea about the polysaccharides. Hot water dissolvability is more than that of cold water dissolvability due to hydrolysis of polysaccharides. The Fig. 1 showed that the variation in cold and hot water dissolvability. The high temperature water method evacuates a piece of unessential segments, for example, inorganic compounds, tannins, starches etc. present in sample. In general, the lower value of cold and hot water soluble contained higher lignin content. In this study the value of cold and hot water dissolvability has been found higher than other woods so as a result samples contain lower lignin content $^{14,15}$.

\section{$1 \%$ Sodium Hydroxide solubility}

Lewin and Goldstein ${ }^{9}$ stated that preparations by extraction with aqueous alkaline solution resulted in isolation of hemicelluloses or form holocellulose. Not as much as normal molecular mass starches like hemicellulose and low quality Cellulose expelled by warm soluble alkali arrangement. $1 \% \mathrm{NaOH}$ Solubility of $\mathrm{S} 1$ was found maximum $(42.05 \%)$ and minimum at S2 $(39.50 \%)$. Table1 showed that solubility of samples little varied. In Fig. 1, the variation in solubility of sample $S 1$ due to temperature. In this study, the solubility of wheat straw in $1 \% \mathrm{NaOH}$ has been higher than other woods ${ }^{1,15}$. The higher $1 \% \mathrm{NaOH}$ solvency of wheat straw might be because of the nearness of low molar mass starches and other alkali dissolvable materials ${ }^{24}$.

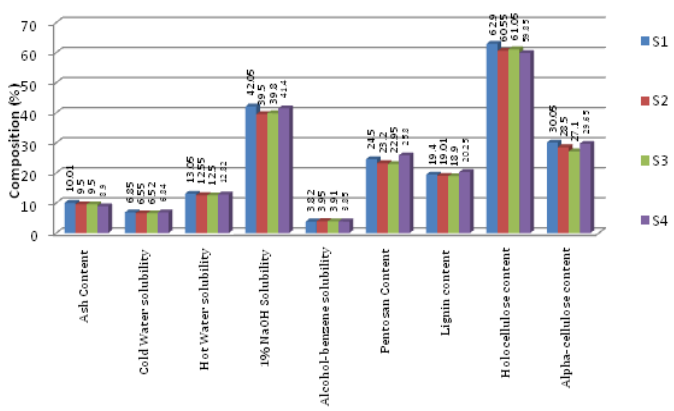

Fig.1. Comparison of Physical and chemical parameters at different sampling sites

Table. 1: Physical and chemical investigation of four samples of Wheat Straw

\begin{tabular}{lcccc}
\hline Parameters as Weight \% /Sampling Site & S1 & S2 & S3 & S4 \\
\hline Ash content & 10.01 & 9.5 & 9.5 & 8.9 \\
Cold water solubility & 6.85 & 6.55 & 6.52 & 6.84 \\
Hot water solubility & 13.05 & 12.55 & 12.50 & 12.82 \\
1\% NaOH solubility & 42.05 & 39.50 & 39.80 & 41.40 \\
Alcohol - benzene solubility & 3.82 & 3.95 & 3.91 & 3.85 \\
Pentosan content & 24.50 & 23.20 & 22.95 & 25.8 \\
Lignin content & 19.40 & 19.01 & 18.90 & 20.25 \\
Holocellulose & 62.90 & 60.55 & 61.05 & 59.85 \\
Alpha cellulose & 30.05 & 28.50 & 27.10 & 29.65 \\
\hline
\end{tabular}




\section{Alcohol - benzene dissolvability}

Ethanol -benzene Extractives is unpolar and removes the vast majority of the ether solvent in addition to a large portion of the natural materials dissolvable in water. The blend, Ethanol-benzene, seems to give the most entire evacuation of lingering dissolvable extractable substances. Table. 1 Ethanol-benzene dissolvability of sample S2 was maximum (3.95\%) and minimum (3.82\%) at S1. Fig. 1 showed that all samples have approximately same values of Ethanol-benzene solubility. The Ethanolbenzene extractives include resins, waxes, tannin, etc. which are usually not quickly biodegradable. The removed content after pretreatment was favorable for improving biodegradability and biogas manufacture. In these study, Ethanol-benzene solubility in samples is little more than other woods ${ }^{15,23}$. This indicates that wheat straw contains compounds such as lipids, less than average molecular mass carbohydrates and another water dissolving materials ${ }^{24}$.

\section{Pentosan content}

Pentosan content examination showed the quantities of sugar which consist of five carbons are obtainable in farming remains. Pentosan content of samples S4 has maximum (25.8\%) and minimum $(22.95 \%)$ at S3. Fig. 1 show variation in the sample S4 and S3 due to the reason of moisture. Pentosan content gives an idea about of noncellulosic polysaccharides or hemicellulose. In samples, Pentosan content value is less than other woods $^{14,15}$. Lesser estimation value of pentosan content to evade the carbohydrates degradation.

\section{Lignin content}

Lignin content is fragrant, formless substance includes phenolic methyl and other components. It is non-fibrous cementing substance which gives strength and rigidity to the cell wall of the fibers. Assurance of lignin content in crude materials gives data to assessment and utilization of the procedures like consummation of cooking cycle. Sample of lignin content S4 was maximum (20.25\%) and minimum (18.90\%) at S3 in Table1. Fig. 1 showed little variation in sample S3 and S4 due to soil fertility. In this study, lignin content in samples has been found lesser then other woods due to these samples take less time for the consumption of cooking liquor, fewer chemicals and less energy ${ }^{1,8,15}$

\section{Holocellulose}

This incorporate Alpha-cellulose and hemicellulose. Detachment of the cellulose in mash into Alpha-, beta-and gamma-cellulose divisions is fractions is an empirical procedure and has been widely used to evaluate samples for various purposes. Holocellulose gives a thought regarding of sinewy crude material. The value of holocellulose in sample $\mathrm{S} 1$ has been found maximum (62.90\%) and minimum (59.85\%) at S4 showed in Table1. Fig. 1 indicates variation in samples by the climatic conditions. Results showed that Holocellulose Content lesser in samples than other woods ${ }^{1,15}$.

\section{Alpha cellulose}

Alpha cellulose signifies high quality, high molecular mass Cellulose content, the $\alpha$-cellulose signifies that of low quality Cellulose and the $\alpha$-cellulose comprises predominantly of hemicellulose. Alpha cellulose in sample S1 was maximum (30.05\%) and minimum $(27.10 \%)$ at S3. In Fig. 1, little variations were shown due to soil type. Alpha-cellulose Content in samples was lower than woods ${ }^{1,4}$.

\section{CONCLUSION}

The synthetic properties of Wheat Straws acquired from four districts of Himachal Pradesh Bilaspur, Hamirpur, Mandi and Kangra were determined. These included Ash content, Cold water dissolvability, Hot Water dissolvability, $1 \% \mathrm{NaOH}$ dissolvability, Ethanol-benzene dissolvability, Pentosan content, Lignin content, Holocellulose and Alpha cellulose. The outcomes gotten from this demonstrate that the diverse examples have distinctive physical and synthetic properties might be because of varieties in climatic conditions, soil sort and manure utilized. The results obtained show that Cellulose contents (holocellulose and alpha cellulose) in wheat straw are little less than hardwood and softwood. The ash content in wheat straw has been higher than other wood. Benefits of higher ash content are high efficiency of decomposition and low consumption of reagent. Cold water solubility results in Table1 showed that S1 has higher $6.85 \%$ and S3 lowest $(6.52 \%)$. Hot water solubility of $\mathrm{S} 1$ was maximum $(13.05 \%)$ and minimum at S3 (12.05\%). Hot water solubility 
indicates that wheat straw contains higher quantity water soluble carbohydrates such as gums, starch, inorganic compound, glycosides, etc. Solubility of wheat straw in $1 \%$ sodium hydroxide solution found greater than woods, so wheat straw example can't be put away for a more extended period. Solvency of Wheat Straw in $1 \%$ sodium hydroxide arrangement might be more noteworthy caused by not as much as normal molecular weight starches. Holocellulose, Alpha-cellulose content in wheat straw found less than other woods. This study reveals that these results may be useful for the study of isolation of Cellulose and Methylcellulose.

\section{ACKNOWLEDGEMENT}

I might want to offer my most profound thanks to my Supervisor, Assoc. Prof. Dr. Yogesh Kumar Walia for.Walia for his steady direction, support and consolation all through my examinations. I might likewise want to stretch out my gratitude to the Mr. Sunil Kumar lab right hand of the bureau of science for their assistance in offering me the assets in running the investigation. I wish to thankful to Vice Chancellor of Career Point University, Hamirpur, (H.P.), India for providing necessary laboratory facilities to undertake these investigations. At long last, I wish to thank my folks for their help and consolation all through my investigation.

\section{REFERENCES}

1. Andrzej, K. B.; Abdullah, A. M. and Jurgen, V. Institute Fur. Werkstofftechnik, Kunststoffe and Recycling technik, University of Kassel, Monchebergstrasse, 3, 34125, Kassel, Germany, Part A, 2010, 41, 480-488.

2. Atchison, J. E. TAPPI Journal, 1996, 79 (10), 87-95.

3. Browning, G.L. Wood Chemistry, Wiley Interscience New York, 1955, 2.

4. El-Sakhawy, M.; El-Samahy, A.M.; Abdlhakim, A. A. and Amal, H. A. National Research Centre, Cellulose and Paper Department, El-bohoth St., Dokki, Cairo, Egypt, IOSR Journal of Applied Chemistry, Ver. II., 2015, 8(1) 41-46.

5. Hon, D. N. S. In Natural Polymers and Agro fibers Composites. E. Frollini, A. L. Leao y L.H.C. Mattoso, 2000, 1-14.

6. Han, J. S. Proceedings of the Korean society of wood science and technology annual meeting, 1998, 3-12.

7. Han, J. S. and Rowell, J.S. CRC Press, 1996, 83-134.

8. Hon, D. N. In: Hon D. N. S. (ed.) Chemical modification of lignocellulosic materials, Dekker, New York, 1996, 1-10.

9. Lewin, M. and Goldstein, I. S. Wood structure and composition, New York, Marcel Dekker, Inc., 1991.

10. Mckean, W. T. and Jacobs, R.S. Wheat Straw as a Study Fiber Source, Tech. Rep. Recycling Technology Assistance Partnership, Clean
Washington Centre, Seattle, Washington, 1997.

11. Nick, D. D. and Emmanuel, G. K. Agricultural crops and residues as feed stocks for nonfood products in Western Europe, Industrial Crops and Products, 2000, 11, 97-106.

12. Oggiano, N.; Angelini, L. G. and Cappelletto, P. Industrial crops and products, 1997, 7(1), 59-67.

13. Pande, H. Non-wood fiber and global fiber supply, Unasylva, 1998, 193(49), 44-50.

14. Pettersen, R. C. Chemical composition of Wood, American chemical society, Chapter 2, 1984, 58-126.

15. Sharma, A. K.; Dutt, D.; Upadhyaya, J. S. and Roy, T. K. Bioresources, 2011, 6(4), 50625073.

16. TAPPI (US Technical Association of Pulp and Paper Industry), norm T $204 \mathrm{~cm}$ - 97, 1997.

17. TAPPI (US Technical Association of Pulp and Paper Industry), norm T 222 om 02, 2002.

18. TAPPI (US Technical Association of Pulp and Paper Industry), norm T $223 \mathrm{~cm}$ 01, 2001.

19. TAPPI (US Technical Association of Pulp and Paper Industry), norm T $203 \mathrm{~cm} \mathrm{99,} 1999$.

20. TAPPI (US Technical Association of Pulp and Paper Industry), norm T $204 \mathrm{~cm}$ 97, 1997.

21. TAPPI (US Technical Association of Pulp and Paper Industry), norm T 212 om 02, 2002.

22. TAPPI (US Technical Association of Pulp and 
Paper Industry), norm T $207 \mathrm{~cm}$ 97, 1997.

23. Zhou, Q.; Lu, X. X. and Huang, L. H. China Wood Ind., 1999, 13(1), 23-25.

24. Singh, S.; Dutt, D. and Tyagi, C. H. BioResources, 2011, 6(4), 3876-3882.

25. Walia, Y. K.; Kishore, K.; Vasu, D. and Gupta, D. K. International Journal of Theoretical
Sciences and Applied Sciences, 2009, 1(2), pg. 15-18.

26. Walia, Y. K. Asian Journal of Applied and Basic Sciences, 2013, 1(1), 40-44.

27. Kumar, S. and Walia, Y. K. Asian J. of Adv. Basic Sci., 2014, 2(3), 12-22. 